Special issue of the 2nd International Conference on Computational and Experimental Science and Engineering (ICCESEN 2015)

\title{
An EPR Study on Radiation-Induced 2-(piperidin-1-ylmethyl)phenol Single Crystal
}

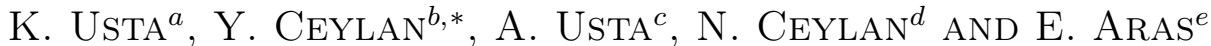 \\ ${ }^{a}$ Alanya Alaaddin Keykubat University, Department of Metallurgical and Materials Engineering, Antalya, Turkey \\ ${ }^{b}$ Selcuk University, Department of Physics, Konya, Turkey \\ ${ }^{c}$ Alanya Alaaddin Keykubat University, Department of Mechanical Engineering, Antalya, Turkey \\ ${ }^{d}$ Giresun University, Department of Chemistry, Giresun, Turkey \\ ${ }^{e}$ Gazi University, Department of Physics, Ankara, Turkey
}

\begin{abstract}
For the assessment of irradiation influence on 2-(piperidin-1-ylmethyl)phenol single crystals $\left(\mathrm{C}_{12} \mathrm{H}_{17} \mathrm{NO}\right)$, electron paramagnetic resonance measurements were carried out on the samples exposed to ${ }^{60}$ Co radiation at dose values of 22.8, 45.6 and $68.4 \mathrm{kGy}$ at room temperature. Electron paramagnetic resonance signals were not observed in non-irradiated sample and in samples irradiated at dose values of 22.8 and $45.6 \mathrm{kGy}$. The electron paramagnetic resonance measurements were performed on the single crystals. This irradiated single crystal was rotated in steps of $10^{\circ}$. One type of radical center was found. The average values of $g$ and hyperfine constant of the detected radiation damage center were calculated from experimental spectra as follows: $g=2.0052, A_{\mathrm{H}}=0.74 \mathrm{mT}$.
\end{abstract}

DOI: 10.12693/APhysPolA.130.178

PACS/topics: 87.66.Uv, 36.20.Kd, 39.30.+w, 33.35.+r

\section{Introduction}

Phenols, known as carbolic acid, are toxic. Therefore, they are pollutants of priority concern. Phenol and its derivatives, such as 2-(piperidin-1-ylmethyl)phenol (2P1MP), are commonly found in oil refining and pharmaceutical industrial products, in steel industries and in domestic products [1]. Various methods have been proposed for treatment of waste waters for removal of phenol [2], however the degradability of phenol is limited [3]. In the recent years, ionizing radiation has gained in interest for sterilization of drug, pharmaceutical, etc. systems. Ionizing radiation, such as gamma-radiation can disinfect the contaminated products $[4,5]$. Occasionally, the irradiation causes breaking of bonds in the structures [6-9]. Electron paramagnetic resonance (EPR), which is a powerful spectroscopic method, has been used for the assessment of the concentration and life-time of the free radicals formed in the studied substance.

In this study, we have investigated the radical structures produced in the irradiated 2P1MP sample using EPR method. Lopez-Monoz et al. have studied the phenol structure added to polycrystalline titanium dioxide in which the compound was induced by photo-oxidation. They have detected $\mathrm{OH}$ radicals in the induced substance [10]. In the literature, so far, no published data has been available about the irradiated 2-(piperidin-1ylmethyl)phenol.

\section{Materials and methods}

In this study, 2-(piperidin-1-ylmethyl) phenol powder material was purchased from Merck. The single crystals

\footnotetext{
* corresponding author; e-mail: yceylan@selcuk.edu.tr
}

of 2-(piperidin-1-ylmethyl) phenol were produced by slow evaporation of aqueous solution in the University of Nigde. These single crystal samples were irradiated by using ${ }^{60} \mathrm{Co}$ source at dose values of $22.8,45.6$ and $68.4 \mathrm{kGy}$. One of single crystals, irradiated at dose rate of $68.4 \mathrm{kGy}$, was mounted on a quartz rod sample holder and this single crystal was rotated in three planes ( $x y$, $x z$, and $y z$ ) during measurements. The EPR spectra were recorded using Bruker EMX 081 spectrometer (x-band, Germany). The spectrometer was set as follows: the microwave power was $3 \mathrm{~mW}$, the modulation frequency of the magnetic field was $100 \mathrm{kHz}$, and modulation amplitude was $0.05 \mathrm{mT}$. Following irradiation, EPR measurements were performed in about two minutes at room temperature.

\section{Results and discussion}

EPR signals were not observed in non-irradiated sample and in sample irradiated at dose values of 22.8 and $45.6 \mathrm{kGy}$. The detailed EPR measurements

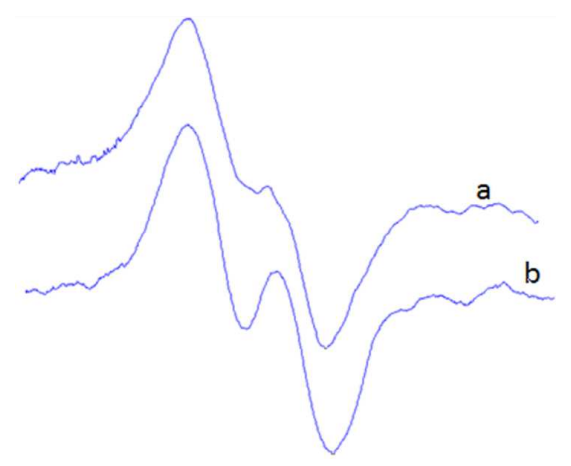

Fig. 1. The EPR spectra of irradiated $\mathrm{C}_{12} \mathrm{H}_{17} \mathrm{NO}$ single crystal rotated in the $y z$-plane by (a) $60^{\circ}$ and (b) $90^{\circ}$ around the $x$-axis of the crystal. 
were performed only on sample with absorbed dose of $68.4 \mathrm{kGy}$, at room temperature. With the rotation of the single crystal in steps of $10^{\circ}$ around itself in the magnetic field, a gradual change of the shape of EPR spectrum was observed. The angle dependence of the EPR lines is shown in Fig. 1.
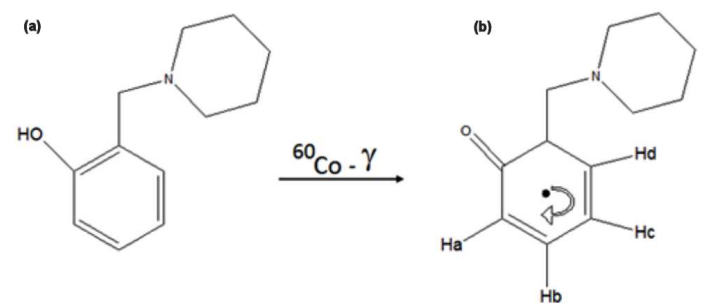

Fig. 2. Molecular structure (a) and radical structure (b) of 2-(piperidin-1-ylmethyl)phenol.

Considering the recorded spectra, we detect one type of radical center. Taking into account analysis based on the recorded spectra and the molecular structure (Fig. 2a), it was concluded that free electron produced by breaking of the $\mathrm{C}-\mathrm{H}$ bond was captured by the benzene ring and the captured free electron is delocalized in the ring. Due to four hydrogen atoms magnetically equivalent in the structure, 1:4:6:4:1 intensity ratios should be observed in the spectrum. However some of these intensity ratios were not observed. We have decided that this is related with presence of impurity in the crystal structure. The contribution of the gamma irradiation may be attributed to the reaction, shown in Fig. 2. The obtained results were verified by computer simulation, shown in Fig. 3 .

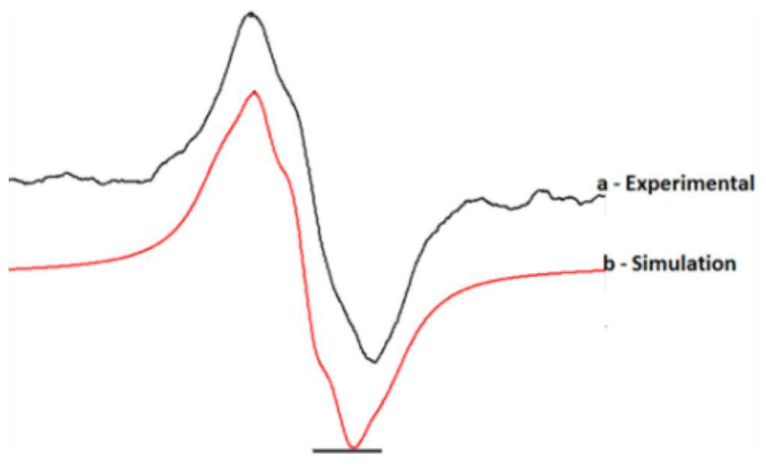

Fig. 3. EPR spectrum of the single crystal rotated in the $x z$-plane by $90^{\circ}$ around $y$-axis of the crystal at room temperature and its simulation.

The determined radical structure was identified and the hyperfine coupling constant and $g$ values calculated from the recorded spectra for the proposed radical structures are shown in Table I. The characteristic spectra were obtained for other orientations of the magnetic field in three orthogonal planes. From the hyperfine values in Table I we have deduced that the single crystal structure exhibited anisotropic characteristics. The angular variations of $g$ and hyperfine coupling constant values for the proposed radical structure are shown in Fig. 4.

TABLE I

The principal values of EPR parameters and direction cosines for the 2-(piperidin-1-ylmethyl)phenol radicals.

\begin{tabular}{|c|c|c|c|c|c|}
\hline \multirow[t]{3}{*}{ Radical } & \multicolumn{2}{|c|}{$\begin{array}{c}\text { EPR parameters } \\
\text { Principal values (Gauss) }\end{array}$} & \multicolumn{3}{|c|}{ Direction cosines } \\
\hline & $\begin{array}{c}A_{\mathrm{H}} \\
\left(H_{a}, H_{b}, H_{c}, H_{d}\right)\end{array}$ & $\begin{array}{c}A_{X X}=9.25 \\
A_{Y Y}=7.19 \\
A_{Z Z}=5.65 \\
A_{\text {aver }}=7.4\end{array}$ & $\begin{array}{c}0.937467139 \\
-0.154458766 \\
0.311926038\end{array}$ & $\begin{array}{c}-0.282273859 \\
0.186976169 \\
0.940936438\end{array}$ & $\begin{array}{r}-0.203658616 \\
-0.970145557 \\
0.131684342\end{array}$ \\
\hline & $g$ & $\begin{aligned} g_{X X} & =2.0065 \\
g_{Y Y} & =2.0047 \\
g_{Z Z} & =2.0044 \\
g_{\text {aver }} & =2.0052\end{aligned}$ & $\begin{array}{l}0.175057651 \\
0.255678552 \\
0.950780362\end{array}$ & $\begin{array}{c}-0.982199951 \\
-0.021446856 \\
0.186609993\end{array}$ & $\begin{array}{c}0.068103422 \\
-0.966523932 \\
0.247373025\end{array}$ \\
\hline
\end{tabular}

The errors for all calculated $g$-values and for hyperfine splittings are estimated as \pm 0.0005 and $\pm 0.05 \mathrm{mT}$

\section{Conclusions}

EPR signal was not observed in the non irradiated control sample. The radical structure produced in methyl2-piperidinomethyl-phenols by ionized gamma radiation was investigated by EPR method. The irradiation can cause breaking of the bonds in the structures. It was concluded from the analysis of the recorded spectra and the obtained parameters that the free radical was created by breaking of the carbon-hydrogen bond and the unpaired electron was delocalized on the carbon. The characteristic spectra were obtained for different orientations of the sample in the magnetic field. From the spectra and from the calculated hyperfine constant values it was determined that the single crystal structure has anisotropic characteristics. 

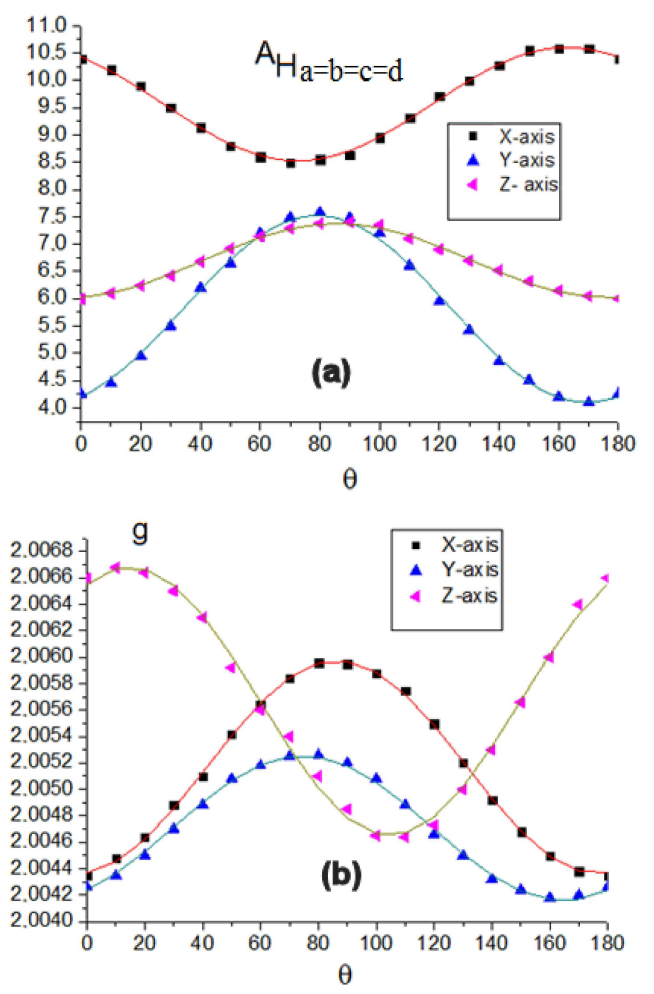

Fig. 4. Angular variations of the hyperfine coupling constant (a) and $g$ values (b) of the radical.

\section{Acknowledgments}

This work is partially supported by the Alanya Alaaddin Keykubat University, BAP offices of Selcuk, and Gazi Universities.

\section{References}

[1] S.H. Lin, R.S. Juang, J. Environ. Manag. 90, 1336 (2009).

[2] J Paca Jr, V. Kremlackova, M. Turek, V. Sucha, L. Vilimkova, J. Paca, M Halecky, Enzyme Microb. Tech. 40, 919 (2007).

[3] C. Zidi, R. Tayeb, M.B. Sik Ali, M. Dhahbi, J. Membrane Sci. 360, 334 (2010).

[4] J.B. Kowalski, A.S. Yan, A. Tallentire, Radiat. Phys. Chem. 58, 77 (2000).

[5] J.B. Kowalski, C. Herring, L. Baryschpolec, Radiat. Phys. Chem. 64, 411 (2002).

[6] D. Boxue, G. Yu, Polymer Deg. Stab. 94, 139 (2009).

[7] E. Aras, B. Asik, B. Caliskan, M. Buyum, M. Birey, Radiat. Effect. Def. Solid, 159, 353 (2004).

[8] A. Usta, H. Cingilli Vural, K. Usta, E. Aras, Y. Ceylan, A. Ozmen, J. Phys. Org. Chem. 24, 635 (2011).

[9] Y. Ceylan, K. Usta, A. Usta, H. Yumurtaci Aydogmus, A. Guner, J. Mol. Struct. 1100, 180 (2015).

[10] M.J. Lopez-Munoz, J. Soria, J.C. Conesa, V. Augugliaro, Stud. Surf. Sci. Catal. 82, 693 (1994). 